A survey of patient acceptance of resect and discard for diminutive polyps

\author{
Douglas K. Rex, M.D. ${ }^{1}$ \\ Nedhi J. Patel, B.S., M.S. ${ }^{2}$ \\ Krishna C. Vemulapalli, M.B.B.S., M.P.H. ${ }^{1}$
}

1. Department of Medicine, Division of Gastroenterology/Hepatology, Indiana University School of Medicine, Indianapolis, Indiana

2. Indiana University School of Medicine, Indianapolis, Indiana

Address correspondence and reprint requests to:

Douglas K. Rex

University Hospital

550 N. University Blvd., Suite 4100

Indianapolis, IN 46202

Phone: (317) 948-8741

Fax: (317) 944-5449

This work was funded by gifts from Scott and Kay Schurz of Bloomington, Indiana and Daniel and Joan Fitzgibbon of Indianapolis, Indiana.

This is the author's manuscript of the article published in final edited form as:

Rex, D. K., Patel, N. J., \& Vemulapalli, K. C. (2015). A survey of patient acceptance of resect and discard for diminutive polyps. Gastrointestinal Endoscopy, 82(2), 376-380.e1. http://doi.org/10.1016/j.gie.2015.04.029 


\begin{abstract}
Background and Aims: Resect and discard is a new paradigm for management of diminutive colon polyps. Little is known regarding whether patients would accept resect and discard. We surveyed colonoscopy patients and their drivers regarding acceptance of resect and discard.
\end{abstract}

Methods: This was a cross-sectional survey of colonoscopy outpatients and their drivers at 2 outpatient academic endoscopy centers.

Results: Four hundred fifteen colonoscopy patients and 293 drivers completed the survey (93.5\% of all invited subjects). Results for the 2 groups were similar. Overall, $66.3 \%$ indicated they would accept resect and discard. Subjects who were younger, white, and seen at the ambulatory surgery center (vs the hospital outpatient department) were more likely to accept. Those declining resect and discard were more likely to be willing to pay some amount out-ofpocket to have diminutive polyps checked by pathology (97.1\% vs $44.5 \%)$. Of those unwilling to accept resect and discard, $49.8 \%$ would require a zero chance of cancer in diminutive polyps before accepting resect and discard.

Conclusions: Patient acceptance of resect and discard appears promising but is quite variable. Eliciting individual patient acceptance of resect and discard will be important during initial implementation into clinical practice. 
Introduction

"Resect and discard" is a new paradigm for management of diminutive colon polyps in which the pathology of polyps is first estimated using endoscopic criteria, and then polyps interpreted as conventional adenomas versus belonging to the serrated class (hyperplastic polyps or sessile serrated polyps) are resected and discarded without pathologic assessment ${ }^{1,2}$.

Resect and discard has been estimated to be a cost-effective management paradigm for diminutive polyps ${ }^{3,4}$. Several tools for endoscopic determination of colon polyp pathology, including narrowband imaging, confocal laser microscopy, Fujinon intelligent chromoendoscopy, and Pentax i-SCAN have been shown to provide adequate accuracy in realtime determination of pathology to support the resect and discard paradigm ${ }^{5,6}$.

In order for resect and discard to enter clinical practice, the paradigm would first need endorsement as a standard of care by professional societies ${ }^{7}$, and acceptance in local institutional policies.

Though potential strategies for implementation of a resect and discard paradigm have been outlined, the reaction of patients to the use of resect and discard has not been examined. In this study we report a survey of 708 patients and potential patients (drivers and other individuals accompanying patients) to our endoscopy unit regarding their attitudes toward the resect and discard paradigm. 
Methods

Research coordinators approached colonoscopy outpatients in our endoscopy units, and/or their driver or other accompanying adult. Potential subjects were included on a consecutive basis if there was a coordinator available to invite participation, if they were age 18 years or older, and if they spoke fluent English. Surveys were performed in the assessment area of the endoscopy unit. The survey was completed between May and September 2014. The patient's drivers or family members were variably with the patient in the assessment area and available for invitation. If not in the assessment area, these individuals were not approached in the endoscopy unit waiting room for participation. Demographic information was collected on age, gender, race, numbers of prior colonoscopies, whether or not polyps had been removed during previous colonoscopies, and the number of years of education completed (appendix A). Survey subjects were then asked to read a short series of paragraphs on the resect and discard concept (appendix A), including information on the prevalence of cancer in polyps of different sizes. They were then asked to check whether they would be willing to have tiny polyps thrown away, or unwilling (appendix A); how much they would be willing to pay per tiny polyp removed to have it checked by a pathologist provided they had to make the payment themselves; and finally, for those who were unwilling to have tiny polyps discarded, they were asked to designate what chance of cancer in a polyp would be necessary before they would be willing to have tiny polyps discarded (appendix A). 
Statistical analysis

Assuming that $50 \%$ of people would say yes to resect and discard, 384 patient participants were needed to estimate the prevalence of persons willing to accept resect and discard with a 5\% margin and a $95 \%$ confidence interval. Drivers and other attendees were also invited to participate but were not counted toward the sample size goal to make certain there was sufficient participation by actual colonoscopy patients. Differences among the groups were analyzed using chi-square tests for categorical variables and independent samples t-tests for continuous variables. Statistical significance was set at 0.05 . We performed a logistic regression on the willingness to accept resect and discard using the variables that were significantly different in univariate analyses when comparing the groups responding yes versus no to resect and discard. We used Hosmer-Lemeshow goodness-of-fit to test for the regression model. Among those willing to pay for pathology, the 2 groups responding yes versus no to resect and discard were compared using Wilcoxon-Mann-Whitney non-parametric test for differences in payment amount. All analyses were performed on SPSS Version 22 (IBM, NY).

Results

There were 442 colonoscopy patients aged $\geq 18$ years approached to complete the survey. Of these, 16 refused, 8 did not speak fluent English, and 3 were considered by the research coordinator unable to comprehend the survey. There were 315 drivers approached, of whom 12 refused, 9 did not speak fluent English, and one was considered unable to comprehend the 
survey. Thus, 708 of 757 (93.5\%) persons approached completed the survey. Subjects who completed the survey included 415 colonoscopy patients and 293 drivers. Table 1 shows several features of the patients and drivers. There was no difference between patients and drivers with regard to their preferences for resect and discard (Table 1) and other survey results, so the results for patients and drivers were combined.

The mean age of all surveyed subjects was 54.9 years, $41 \%$ were male, $91.8 \%$ underwent colonoscopy at the outpatient hospital department and only $8.2 \%$ at the ambulatory surgery center, $84.9 \%$ were white, $1.5 \%$ Hispanic, and most of the remaining subjects were black. Of all participating subjects, 500 (70.4\%) had a prior colonoscopy, and of these $281(56.2 \%)$ had prior polyps. The mean number of years of education was 14.8 .

Of all 708 survey subjects, 471 (66.3\%) expressed a willingness to have polyps $\leq 5 \mathrm{~mm}$ in size discarded.

Table 2 shows univariate analyses comparing the 471 subjects willing to have polyps discarded and the 239 subjects who were unwilling. In univariate analyses, those willing to participate in resect and discard were younger, more likely to be seen at the ambulatory surgery center, to be white, and to have never had colonoscopy (Table 2). Multivariate analysis demonstrated that being seen at the ambulatory surgery center $(p<0.001)$, younger age $(p=0.009)$ and white race $(\mathrm{p}=0.027)$ were associated with acceptance of resect and discard, but absence of a prior colonoscopy was not $(\mathrm{p}=0.34)$. 
There were a total of 440 subjects who said they were willing to pay some amount for pathologic assessment of their polyps (Table 3). Those who said they would accept resect and discard were less likely to be willing to pay some amount for pathology compared with those unwilling to accept resect and discard (44.5\% vs $97.1 \%$; $\mathrm{p}<0.001)$. There were 139 persons who checked amounts $<\$ 100$ as what they would be willing to pay, 161 checked $\$ 100$ (the single-most commonly quoted amount), 68 checked amounts from $\$ 200$ to $\$ 400$, and 82 checked amounts $\geq \$ 500$. The amounts checked by those unwilling to accept resect and discard were larger than those checked by the group willing to accept resect and discard ( $\mathrm{p}<0.001$; Table 3).

\begin{abstract}
Among the 239 individuals who said they were unwilling to permit discarding polyps, most of the individuals wanted an extremely low risk of cancer before they would be willing to discard polyps, and $49.8 \%$ said there would be need to be a zero chance of cancer before they would agree to discarding polyps (Table 4).
\end{abstract}

Discussion

In this study, we reported a survey of willingness of colonoscopy patients and their drivers (typically family members or friends) to participate in a resect and discard policy for diminutive polyps. Strengths of the study include the high response rate produced by the in-person administration of the survey, and the large number of subjects surveyed. 
The results show a wide range of patient perceptions of resect and discard. A majority of subjects (66\%) was willing to have polyps $\leq 5 \mathrm{~mm}$ in size discarded, given the risk of cancer of less than 1 in 1,000. Evidence indicates that the risk of cancer is indeed well below 1 in 1000 in diminutive polyps ${ }^{8-20}$. Thus, the survey suggests that many patients would accept resect and discard. However, the survey also indicates that patient input should be elicited regarding the resect and discard before implementation because a minority of patients (1/3) were opposed to resect and discard, and half of these subjects (or 1/6 of the total survey population) said they would want a zero chance of cancer before agreeing to resect and discard.

Thus, our results suggest that in the initial phases of a resect and discard clinical practice, it will be best to solicit each individual patient's attitudes and perceptions regarding resect and discard before proceeding to the resect and discard paradigm in that particular patient. Obviously, patient perception and willingness to participate could be expected to change in one direction or another as the success of resect and discard in actual clinical practice is clarified.

Limitations of this survey are several, including that as a survey it may not represent what patients would actually decide once resect and discard is instituted. Second, the study population may not be representative of many local or regional populations with regard to factors such as race and socioeconomic status. Third, the assumptions provided in the survey may not be accurate, though available evidence ${ }^{8-20}$ indicates that the risk of cancer in diminutive polyps is well below 1 per 1000 . 
In summary, our survey indicates that a majority of patients, provided with information that the risk of cancer in polyps $\leq 5 \mathrm{~mm}$ in size is less than 1 per 1000 , would be willing to have those polyps discarded without submission to pathology. However, the range of perceptions is wide, and a minority of patients at the present time would prefer submission of diminutive polyps to pathology, and about 1 in 6 survey subjects indicated they would need to know that the risk of cancer was zero in diminutive polyps before they would be willing to have diminutive polyps discarded after resection. Thus, in the initial phases of a resect and discard practice, it will be best to solicit information on patient perceptions before deciding whether resect and discard is appropriate for an individual patient. Our survey indicates that additional attention to patient attitudes and education of patients on the rationale for resect and discard will be necessary as the paradigm is introduced into clinical practice. This requirement is one of several issues that must be addressed as the resect and discard paradigm moves forward ${ }^{21}$. 
Appendix A.

\section{Resect and Discard Survey}

This survey is about your opinion on a policy called "resect and discard" which is about the handling of very small colon polyps after they are removed during colonoscopy. We appreciate your time in completing this survey.

Age Male / Female

Hispanic or Non-Hispanic

White African American Asian Other

How many colonoscopies have you had before today?

Did you have polyps on any previous colonoscopy? Yes No N/A

What year did you complete in school?

Here is some preliminary information about colon polyps:

Rarely, a polyp already has cancer in it. This can be important to know because a polyp with cancer may need a follow-up surgery to get the bowel and lymph nodes out. The chance of cancer is related to the size of the polyp as follows

\section{Size}

\section{Chance of cancer}

$10 \mathrm{~mm}$ (about one-third inch) or larger

1 in 100

6-9 $\mathrm{mm}(1 / 4$ to $1 / 3$ of inch)

1 in 500

$5 \mathrm{~mm}$ (about $1 / 4$ inch) or less

less than 1 in 1,000

Some polyps can turn into cancer and some can't. If a polyp has the ability to become cancer in the future it's called "pre-cancerous." Using modern colonoscopes, doctors can tell which are pre-cancerous just by looking at them (accuracy is the same as the pathologist). The only issue affected by whether a polyp is pre-cancerous is when the next colonoscopy should be performed.

In a proposed new policy your colonoscopy doctor could examine polyps that are $5 \mathrm{~mm}$ or smaller in size and determine by their appearance whether they are pre-cancerous or not. These polyps $5 \mathrm{~mm}$ and smaller would then be removed and discarded without being sent to the pathologist. Polyps larger than $5 \mathrm{~mm}$ would still be sent to the pathologist for analysis.

Discarding the tiny polyps after removing them would save significant costs, notably supplies and pathology fees. 
We would like to know how you would feel about this policy. Please check which conclusion describes your reaction best. (Choose between \# 1 and \#2)

1. Throwing away tiny polyps (with less than 1 in 1,000 chance of cancer) after removing them is a good idea. It's a good way to reduce health care costs and I'm OK with it for my colon polyps.

2. This is a bad idea. I want my tiny polyps checked by a pathologist.

Suppose you have to pay for the pathology charges yourself (not your insurance company). Is there a price you'd be willing to pay per tiny polyp removed to have them checked by the pathologist? Please circle the highest charge you'd be willing to pay:

$\$ 25$
$\$ 50$
$\$ 100$
$\$ 200$
$\$ 400$
$\$ 500$
$\$ 1,000$
$\$ 2,000$
$\$ 3,000$
$\$ 4,000$
$\$ 5,000$

More than $\$ 5,000$

Other amount you'd be willing to pay

If you choose number 2, what would be the chance of cancer in a polyp have to be before you'd be willing to have it thrown away and not sent to pathologist?

1. Less than 1 in 2,000

2. Less than 1 in 5,000

3. Less than 1 in 10,000

4. Less than 1 in 20,000

5. Less than 1 in 50,000

6. Less than 1 in 100,000

7. Zero chance of cancer 

friend)

\begin{tabular}{|l|l|l|l|}
\hline & Patient (n=415) & Driver $(\mathbf{n}=\mathbf{2 9 3})$ & -value \\
\hline Age (years) & $55.9(15.2)$ & $53.9(13.8)$ & 0.065 \\
\hline Male sex & $202(48.7)$ & $88(30)$ & $<0.001$ \\
\hline $\begin{array}{l}\text { Hospital outpatient } \\
\text { department vs the } \\
\text { ambulatory surgery } \\
\text { center }\end{array}$ & $373(89.9)$ & $277(94.5)$ & 0.026 \\
\hline $\begin{array}{l}\text { Willing to accept the } \\
\text { resect and discard } \\
\text { paradigm }\end{array}$ & $279(67.2)$ & $191(65.2)$ & 0.57 \\
\hline White (vs non-white) & $349(84.1)$ & $254(86.7)$ & 0.339 \\
\hline $\begin{array}{l}\text { Hispanic (vs non- } \\
\text { Hispanic) }\end{array}$ & $7(1.7)$ & $4(1.4)$ & 0.733 \\
\hline Any prior colonoscopy & $321(77.3)$ & $179(61.1)$ & $<0.001$ \\
\hline Any prior polyps ${ }^{*}$ & $209 / 321(65.1)$ & $72 / 179(40.2)$ & $<0.001$ \\
\hline Education years* & $14.8(3)$ & $14.9(2.7)$ & 0.82 \\
\hline $\begin{array}{l}\text { Willing to pay any } \\
\text { amount for pathology }\end{array}$ & $259(62.4)$ & $181(61.8)$ & 0.864 \\
\hline
\end{tabular}

tamong 500 participants with prior colonoscopy

*one patient refused to indicate years of schooling 
Table 2. Comparison between survey subjects who were willing versus unwilling to accept a resect and discard paradigm

\begin{tabular}{|l|l|l|l|}
\hline & $\begin{array}{l}\text { Yes to resect and } \\
\text { discard }(\mathbf{n}=\mathbf{4 7 0})\end{array}$ & $\begin{array}{l}\text { No to resect and } \\
\text { discard }(\mathbf{n}=\mathbf{2 3 8})\end{array}$ & p-value \\
\hline Age & $53.9(14.8)$ & $57.4(14.2)$ & 0.003 \\
\hline Male sex & $203(43.2)$ & $87(36.6)$ & 0.09 \\
\hline $\begin{array}{l}\text { Seen at hospital } \\
\text { outpatient department } \\
\text { (vs the ambulatory } \\
\text { surgery center) }\end{array}$ & $417(88.7)$ & $233(97.9)$ & $<0.01$ \\
\hline Patient (vs driver) & $279(59.4)$ & & 0.57 \\
\hline White (vs non-white) & $412(87.7)$ & $136(57.1)$ & 0.01 \\
\hline $\begin{array}{l}\text { Hispanic (vs non- } \\
\text { Hispanic) }\end{array}$ & $8(1.7)$ & $191(80.3)$ & 0.65 \\
\hline Any prior colonoscopy & $320(68.1)$ & $3(1.3)$ & 0.04 \\
\hline Any prior polyps ${ }^{*}$ & $176 / 320(55)$ & $180(75.6)$ & 0.47 \\
\hline Education years* & $15(2.9)$ & $105 / 180(58.3)$ & 0.09 \\
\hline & & $14.6(2.8)$ & \\
\hline
\end{tabular}

tamong 500 participants with prior colonoscopy

*one patient refused to indicate years of schooling 
Table 3. Among 440 patients who were willing to pay something for pathology, the amounts cited by the patients

\begin{tabular}{|l|l|l|}
\hline $\begin{array}{l}\text { Dollar amounts } \\
\text { subjects were } \\
\text { willing to pay }\end{array}$ & $\begin{array}{l}\text { Yes to resect and } \\
\text { discard }(\mathbf{n = 2 0 9 )}\end{array}$ & $\begin{array}{l}\text { No to resect and } \\
\text { discard }(\mathbf{n}=\mathbf{2 3 1})\end{array}$ \\
\hline 5 & $1(0.5)$ & 0 \\
\hline 10 & $5(2.4)$ & $2(0.9)$ \\
\hline 25 & $52(24.9)$ & $17(7.4)$ \\
\hline 50 & $38(18.2)$ & $24(10.4)$ \\
\hline 100 & $74(35.4)$ & $87(37.7)$ \\
\hline 200 & $18(8.6)$ & $32(13.9)$ \\
\hline 250 & $3(1.4)$ & 0 \\
\hline 400 & 0 & $5(2.2)$ \\
\hline 500 & $10(4.8)$ & $43(18.6)$ \\
\hline 1000 & $4(1.9)$ & $10(4.3)$ \\
\hline 2000 & 0 & $1(0.4)$ \\
\hline 4000 & 0 & $1(0.4)$ \\
\hline 5000 & $3(1.4)$ & $3(1.3)$ \\
\hline$>5000$ & $1(0.5)$ & $6(2.6)$ \\
\hline
\end{tabular}

Wilcoxon-Mann-Whitney mean rank for yes group: 176, mean rank for no group: 250, medians for both groups: $100, \mathrm{p}<0.001$ 
Table 4. Among those who said "no" to the resect and discard paradigm, the risk of cancer in diminutive polyps they would require before agreeing to a resect and discard paradigm

\begin{tabular}{|l|r|r|}
\hline $\begin{array}{l}\text { Required cancer risk } \\
\text { in diminutive polyps } \\
\text { to make resect and } \\
\text { discard acceptable }\end{array}$ & Frequency & Percent \\
\hline$<1$ in2000 & 9 & 3.8 \\
$<1$ in5000 & 19 & 7.9 \\
$<1$ in10000 & 18 & 7.5 \\
$<1$ in20000 & 5 & 2.1 \\
$<1$ in50000 & 14 & 5.9 \\
$<1$ in100000 & 55 & 23.0 \\
Zero chance & 119 & 49.8 \\
\hline
\end{tabular}


References

1. Rex DK. Narrow-band imaging without optical magnification for histologic analysis of colorectal polyps. Gastroenterology 2009;136:1174-81.

2. Ignjatovic A, East JE, Suzuki N, Vance M, Guenther T, Saunders BP. Optical diagnosis of small colorectal polyps at routine colonoscopy (Detect InSpect ChAracterise Resect and Discard; DISCARD trial): a prospective cohort study. Lancet Oncol 2009;10:1171-8.

3. Kessler WR, Imperiale TF, Klein RW, Wielage RC, Rex DK. A quantitative assessment of the risks and cost savings of forgoing histologic examination of diminutive polyps. Endoscopy 2011;43:683-91.

4. Hassan C, Pickhardt PJ, Rex DK. A resect and discard strategy would improve costeffectiveness of colorectal cancer screening. Clin Gastroenterol Hepatol 2010;8:865-9, 9 e1-3. 5. McGill SK, Evangelou E, Ioannidis JP, Soetikno RM, Kaltenbach T. Narrow band imaging to differentiate neoplastic and non-neoplastic colorectal polyps in real time: a metaanalysis of diagnostic operating characteristics. Gut 2013;62:1704-13.

6. Wanders LK, East JE, Uitentuis SE, Leeflang MM, Dekker E. Diagnostic performance of narrowed spectrum endoscopy, autofluorescence imaging, and confocal laser endomicroscopy for optical diagnosis of colonic polyps: a meta-analysis. Lancet Oncol 2013;14:1337-47.

7. Rex DK, Kahi C, O'Brien M, et al. The American Society for Gastrointestinal Endoscopy PIVI (Preservation and Incorporation of Valuable Endoscopic Innovations) on real-time endoscopic assessment of the histology of diminutive colorectal polyps. Gastrointest Endosc 2011;73:419-22.

8. Chaput U, Alberto SF, Terris B, et al. Risk factors for advanced adenomas amongst small and diminutive colorectal polyps: a prospective monocenter study. Dig Liver Dis 2011;43:609-

12.

9. Gupta N, Bansal A, Rao D, et al. Prevalence of advanced histological features in diminutive and small colon polyps. Gastrointest Endosc 2012;75:1022-30.

10. Shapiro R, Ben-Horin S, Bar-Meir S, Avidan B. The risk of advanced histology in smallsized colonic polyps: are non-invasive colonic imaging modalities good enough? Int J Colorectal Dis 2012;27:1071-5.

11. Tsai FC, Strum WB. Prevalence of advanced adenomas in small and diminutive colon polyps using direct measurement of size. Dig Dis Sci 2011;56:2384-8.

12. Unal H, Selcuk H, Gokcan H, et al. Malignancy risk of small polyps and related factors. Dig Dis Sci 2007;52:2796-9.

13. Bretagne JF, Manfredi S, Piette C, Hamonic S, Durand G, Riou F. Yield of high-grade dysplasia based on polyp size detected at colonoscopy: a series of 2295 examinations following a positive fecal occult blood test in a population-based study. Dis Colon Rectum 2010;53:339-45.

14. Lieberman D, Moravec M, Holub J, Michaels L, Eisen G. Polyp size and advanced histology in patients undergoing colonoscopy screening: implications for CT colonography. Gastroenterology 2008;135:1100-5.

15. Lawrance IC, Sherrington C, Murray K. Poor correlation between clinical impression, the small colonic polyp and their neoplastic risk. J Gastroenterol Hepatol 2006;21:563-8.

16. Butterly LF, Chase MP, Pohl H, Fiarman GS. Prevalence of clinically important histology in small adenomas. Clin Gastroenterol Hepatol 2006;4:343-8. 
17. Church JM. Clinical significance of small colorectal polyps. Dis Colon Rectum 2004; 47:481-5.

18. Fong TV, Chuah SK, Chiou SS, et al. Correlation of the morphology and size of colonic polyps with their histology. Chang Gung Med J 2003;26:339-43.

19. Aldridge AJ, Simson JN. Histological assessment of colorectal adenomas by size. Are polyps less than $10 \mathrm{~mm}$ in size clinically important? The European journal of surgery = Acta chirurgica 2001;167:777-81.

20. Silva SM, Rosa VF, Santos AC, Almeida RM, Oliveira PG, Sousa JB. Influence of patient age and colorectal polyp size on histopathology findings. Arquivos brasileiros de cirurgia digestiva : $\mathrm{ABCD}=$ Brazilian archives of digestive surgery 2014;27:109-13.

21. Rex DK. Prediction of colorectal polyp pathologic lesions with image-enhanced endoscopy: What will it take to make it matter? Gastrointest Endosc 2014;80:1088-93. 